\title{
Third-order Nonlinear Optical Properties of An Organo-metallic Complex
}

\author{
Jing Sun \\ College of Physics and Mechatronics Engineering \\ Jishou University \\ Xiangxi, P. R. China 416000 \\ e-mail: sunjingsd@aliyun.com
}

\author{
Yikun Zhao \\ Engineering College \\ South of China Agriculture University \\ Guangzhou, P. R. China 510640 \\ e-mail: zhaoyikun@scau.edu.cn
}

\begin{abstract}
The 2-thioxo-1,3-dithiole-4,5-dithiolato (dmit) complexes exhibits very large and fast third-order NLO response and may be promising candidates for the applications in the field of nonlinear optics. An organometallic complex, ethyltriphenylphosphonium bis(2-thioxo1,3-dithiole-4,5-dithiolato)aurate(III) (abbreviated as TPEtAu) is synthesized and the third-order nonlinear optical properties of TPEtAu dissolved in acetonitrile are investigated by $Z$-scan technique with 20 ps pulse width at $1064 \mathrm{~nm}$ and $532 \mathrm{~nm}$, respectively. The TPEtAu sample solution exhibits strong self-defocusing effect both at 1064 $\mathrm{nm}$ and $532 \mathrm{~nm}$, the negative nonlinear refraction coefficients $n_{2}$ are estimated to be as high as $-8.48 \times 10^{-12}$ esu and $-8.26 \times 10^{-12}$ esu, respectively. In additon, a reverse saturable absorption has been found only at $532 \mathrm{~nm}$ and the absorption coefficient $\beta$ is $1.88 \times 10^{-11} \mathrm{~m} / \mathrm{W}$. All the results suggest that TPEtAu has potential for the application of alloptical switching.
\end{abstract}

Keywords-Nonlinear optical properties; self-defocusing effect ; reverse saturable absorption; organo-metallic complex; Z-scan technique

\section{INTRODUCTION}

There has been a large need for nonlinear optical (NLO) materials that can be used for applications such as optical switching, optical bistability, optical limiting and ultrafast optical communications [1-4]. Currently, nonlinear media possessing large nonlinear refractive index $\left(\mathrm{n}_{2}\right)$ at the operating wavelength; minimal absorption; and ultrafast nonlinear refractive index response and relaxation times are of much interest for the application of all-optical switching [5-7]. The 2-thioxo-1,3-dithiole-4,5-dithiolato (dmit) complexes, in which electron donor and acceptor moieties are attached to the extremes of a $\pi$-conjugated structure, are generally used as important building blocks for organic, organometallic and coordination complex electrical conductors and superconductors [8]. In recent years, some investigations to the metal-dmit complexes have shown this class of organo-metallic complex exhibits very large and fast third-order NLO response and may be promising candidates for the applications in the field of nonlinear optics [9-11].

Previously, Our group has studied systematically the third-order NLO properties of dmit complexes by Z-scan technique at $1064 \mathrm{~nm}$ and $532 \mathrm{~nm}$ laser duration [12-14]. The results have presented that many materials possess large third-order NLO coefficients at the operating wavelength. In this work, an organo-metallic material of the $\mathrm{Au}(\mathrm{dmit})_{2}$ salts, ethyltriphenylphosphonium bis(2thioxo-1,3-dithiole-4,5-dithiolato)aurate(III) (abbreviated as TPEtAu) has been synthesized and the NLO properities of its acetonitrile solution were studied by Z-scan technique [15] with $20 \mathrm{ps}$ pulse width at $1064 \mathrm{~nm}$ and 532 $\mathrm{nm}$, respectively. This material shows strong selfdefocusing effect both at $1064 \mathrm{~nm}$ and $532 \mathrm{~nm}$, and reverse saturable absorption at $532 \mathrm{~nm}$. The negative nonlinear refraction coefficients $n_{2}$ and the absorption coefficient $\beta$ were obtained respectively.

\section{EXPERIMENTAL}

Fig .1 shows the chemical structure of TPEtAu molecule. The synthesis of TPEtAu is a modification of literature methods [16]. To degassed dimethyl formamide (DMF, 48ml), $\mathrm{CS}_{2}(24 \mathrm{ml})$ was added and the mixture was cooled to $0{ }^{\circ} \mathrm{C}$. Sodium $(1.45 \mathrm{~g})$ was added to the solution and the mixture under an argon atmosphere was vigorously stirred with cooling until the reaction was completed. Several $\mathrm{ml}$ of $\mathrm{MeOH}$ was slowly added. To the solution, separate solutions of (i) $\mathrm{NaAuCl}_{4} \cdot 2 \mathrm{H}_{2} \mathrm{O}(6.21 \mathrm{~g})$ dissolved in $25-28 \% \mathrm{NH}_{3}(40 \mathrm{ml})$, and (ii) $\mathrm{C}_{24} \mathrm{H}_{20} \mathrm{PBr}(5.80 \mathrm{~g})$ in water $(30 \mathrm{ml})$ were added consecutively with stirring at room temperature. The mixture was stirred overnight, and then the product was isolated by filtration and washed with water and $\mathrm{MeOH}$, to afford brown polycrystals of TPEtAu.

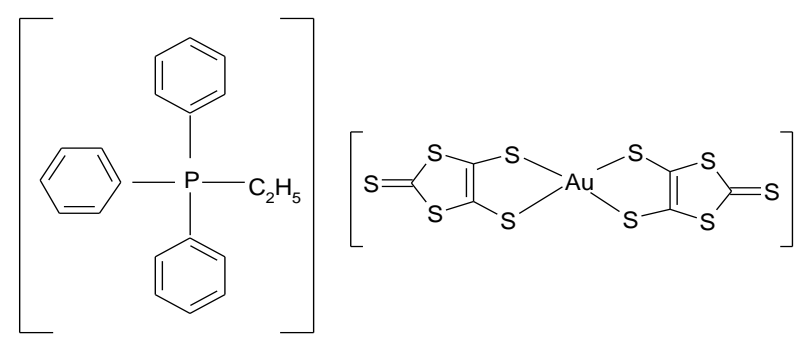

Figure 1. Molecular structure of TPEtAu.

The linear absorption spectrum of TPEtAu dissolved in acetonitrile was recorded by using a UV-vis-NIR scanning spectrophotometer (Hitachi U-4100, Japan) with the wavelength region $300-1100 \mathrm{~nm}$ at room temperature using acetonitrile solvent as reference.

The third-order NLO properties of the acetonitrile solution of TPEtAu with concentration $1 \times 10^{-3} \mathrm{~mol} / \mathrm{L}$ were determined by the Z-scan method [15]. This technique is based on the principle of spatial beam distortion and offers simplicity as well as very high sensitivity for 
distinguishing the contribution of the real part (nonlinear refraction) and the imaginary part (nonlinear absorption) of third-order nonlinear susceptivity $\chi^{(3)}$. In our measurements, a mode-locked Nd:YAG laser provides picoseconds (both full width at half-maximum, FWHM) pulses at $1064 \mathrm{~nm}$ and $532 \mathrm{~nm}$ with a repetition rate of $10 \mathrm{~Hz}$. The sample is moved along the optic axis (the Z-direction) through the focus of the lens, which has a focal length of $150 \mathrm{~mm}$, while the energy transmitted through an aperture in the farfield is recorded as a function of the sample position. The the beam waist radius $\left(\mathrm{w}_{0}\right)$ was measured to be 43.2 and $20.6 \mu \mathrm{m}$, respectively. Accordingly, the corresponding Rayleigh lengths, $\mathrm{z}_{0}$, were calculated to be 5.5 and $2.5 \mathrm{~mm}$. The thickness of a quartz cell containing the sample is 1 $\mathrm{mm}$ which is less than the Rayleigh lengths of the laser beam. The reference beam and the on-axis transmitted beam energy through a closed-aperture (CA) or an openaperture (OA) was measured by an energy ratiometer simultaneously. The CA curve includes both the thirdorder nonlinear refraction and absorption, while the OA curve only includes the latter. Before measuring this sample, the system was calibrated using $\mathrm{CS}_{2}$ in a quartz cell as reference. Measurements on the pure solvent (acetonitrile) in the cell were also performed under the same measuring condition to verify that the Z-scan curves originated from the material, not from the solvent or the quartz cell.

\section{RESULTS AND DISCUSSION}

Fig .2 is the UV-Vis-NIR absorption spectrum of TPEtAu in acetonitrile solution with the wavelength region 200-1100 nm at room temperature. TPEtAu solution exhibits four peaks at 224, 290, 348 and $465 \mathrm{~nm}$ in the $\mathrm{UV}-\mathrm{V}$ is region. The first peak at $224 \mathrm{~nm}$ is confirmed with $\pi-\pi^{*}$ transition of phenyl, while those at 290 and $465 \mathrm{~nm}$ are ascribed to the $\pi-\pi^{*}$ transition of dmit. The peak at $348 \mathrm{~nm}$ is due to the $\mathrm{S} \rightarrow \mathrm{Au}$ interaction. The linear absorption at $1064 \mathrm{~nm}$ is very small.

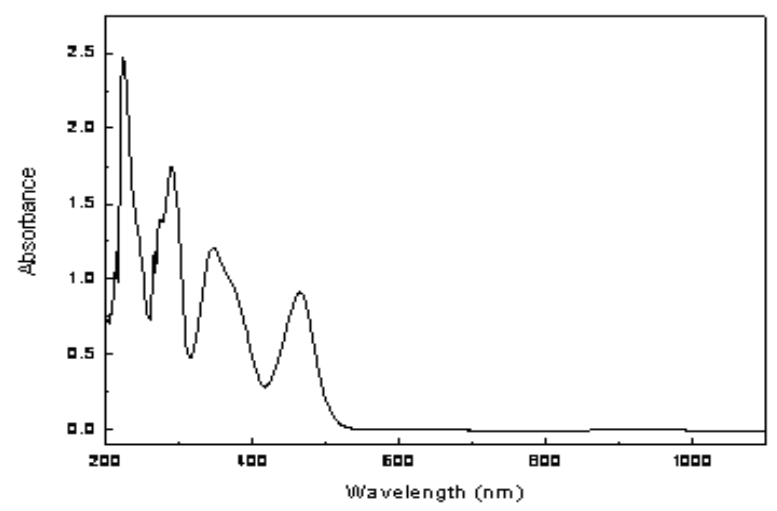

Figure 2. UV-Vis-NIR absorption spectrum of TPEtAu in acetonitrile at room temperature.

Fig .3 shows the far-field OA and the division of the $\mathrm{CA}$ by OA Z-scan curves for the material at $1064 \mathrm{~nm}$ and $532 \mathrm{~nm}$, respectively. For $1064 \mathrm{~nm}$ outside resonant absorption, the OA curve is shown as a horizontal straight line. This demonstrates that no nonlinear absorption occurs at this wavelength. For $532 \mathrm{~nm}$, the OA curve presents a valley at the focus position that is regarded as the reverse saturable absorption (RSA) for the near-resonant absorption at $532 \mathrm{~nm}$. To take out the effect of the

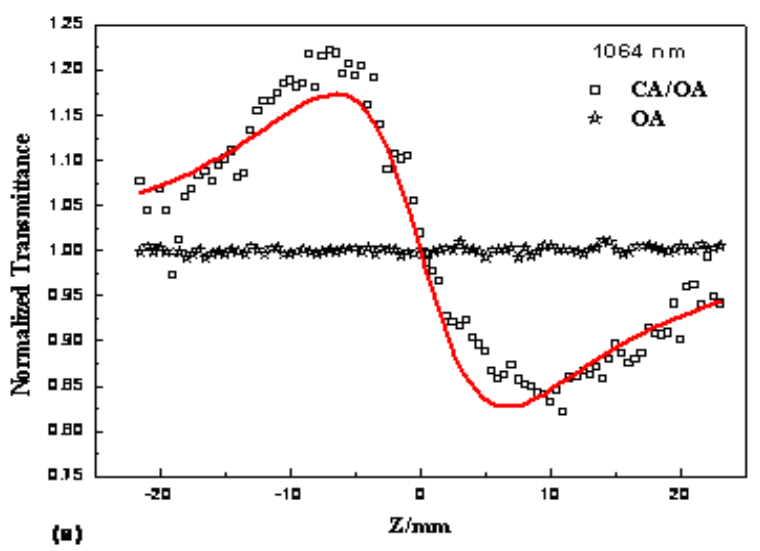

absorption, we used the CA Z-scan curve divided by the OA Z-scan curve. The peak-to-valley configuration of the $\mathrm{CA} / \mathrm{OA} \mathrm{Z}$-scan curves suggest that the sample exhibits self-defocus and the NLO refractive index coefficients are negative both at $1064 \mathrm{~nm}$ and $532 \mathrm{~nm}$. In order to assess the possible contribution of the solvent nonlinearity, we conducted the Z-scan experiments on neat acetonitrile under the same conditions. The results show that there is no effect of the laser beams on the cuvette and acetonitrile.

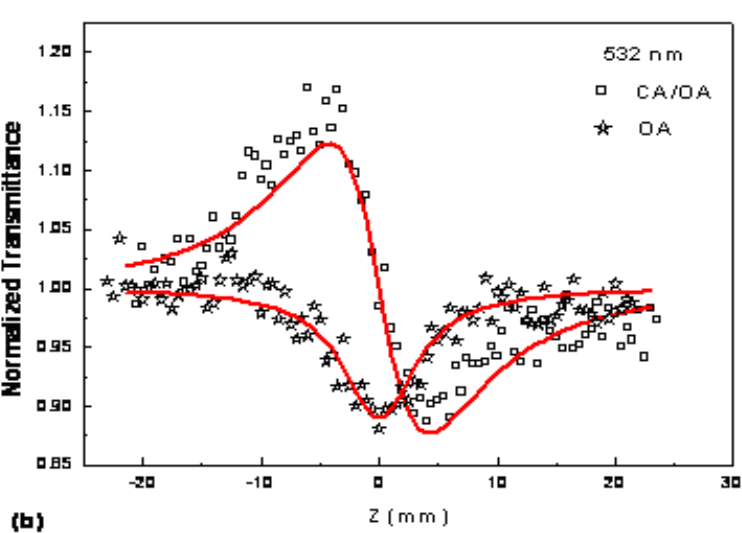

Figure 3. OA and CA/OA Z-scan curves of TPEtAu sample solution illuminated by 20 ps laser pulses at $1064 \mathrm{~nm}$ (a) and $532 \mathrm{~nm}$ (b). The solid lines are the curves fitted to the experimental data using Eq. (1) and Eq. (2). 
The nonlinear absorption coefficient $\beta(\mathrm{m} / \mathrm{W})$ can be measured by fitting the experimental data with the equation [15]:

$$
T_{O A}=\sum_{m=0}^{\infty} \frac{\left[-\beta I_{0} L_{e f f} /\left(1+z^{2} / z_{0}^{2}\right)\right]^{m}}{(m+1)^{3 / 2}}
$$

Where $T_{O A}$ is the normalized transmittance for the OA Zscan curve, $L_{e f f}=\left(1-\exp \left(-\alpha_{0} L\right)\right) / \alpha_{0}$ is the effective thickness of the sample with $\mathrm{L}$ the sample length and $\alpha_{0}$ the linear absorption coefficient, and $\mathrm{I}_{0}$ is the onaxis irradiance at focus.

The NLO refractive index $\mathrm{n}_{2}$ can be obtained by fitting the experimental data with the equation [15]:

$$
\begin{aligned}
& T_{C A / O A}=1+\frac{4 \Delta \Phi_{0} x}{\left(x^{2}+9\right)\left(x^{2}+1\right)} \\
& \Delta \Phi_{0}=k n_{2} I_{0} L_{e f f}
\end{aligned}
$$

Where $T_{C A / O A}$ is the normalized transmittance for the CA/OA Z-scan curve and $\mathrm{x}=\mathrm{z} / \mathrm{z} 0 . \Delta \Phi_{0}$ is the on-axis nonlinear phase shift at focus caused by NLO refractive. $k=2 \pi / \lambda$ is the wave vector. $\mathrm{I}_{0}$ is the on-axis irradiance at focus.

Accordingly, the real and imaginary parts of the $\chi^{(3)}$ of the sample can be calculated by the following equations $[17,18]$ :

$$
\begin{aligned}
& \operatorname{Re} \chi^{(3)}(e s u)=\frac{c n_{0}^{2}}{120 \pi^{2}} n_{2}\left(m^{2} / W\right) \\
& \operatorname{Im} \chi^{(3)}(e s u)=\frac{c^{2} n_{0}^{2}}{240 \pi^{2} \omega} \beta(m / W) \\
& \gamma=\frac{\chi^{(3)}}{N_{c} L}
\end{aligned}
$$

where $\mathrm{n}_{0}$ is the linear refractive index of the sample and $\omega$ is the angular frequency of the light field. $\mathrm{N}_{c}$ is the molecular number density in $\mathrm{cm}^{-3}$ and $\mathrm{L}$ is the local-field

\begin{tabular}{|c|c|c|c|c|c|c|}
\hline $\begin{array}{l}\text { Sample } \\
\text { solution }\end{array}$ & $\begin{array}{c}\lambda \\
(\mathrm{nm})\end{array}$ & $\begin{array}{l}\text { Pulse } \\
\text { width }\end{array}$ & $\begin{array}{c}\mathrm{I}_{0} \\
\left(\mathrm{GW} / \mathrm{cm}^{2}\right)\end{array}$ & $\begin{array}{c}\mathrm{n}_{2} \\
\left(\times 10^{-12} \text { esu }\right)\end{array}$ & $\begin{array}{c}\beta \\
\left(\times 10^{-11} \mathrm{~m} / \mathrm{W}\right)\end{array}$ & $\begin{array}{c}\gamma \\
\left(\times 10^{-31} \mathrm{esu}\right)\end{array}$ \\
\hline \multirow{2}{*}{$\begin{array}{l}\text { TPEtAu in } \\
\text { acetonitrile }\end{array}$} & 1064 & \multirow[b]{2}{*}{$20 \mathrm{ps}$} & 5.50 & -8.48 & 0 & 7.81 \\
\hline & 532 & & 2.05 & -8.26 & 1.88 & 7.97 \\
\hline
\end{tabular}
correction factor which may be approximated by $\left[\left(n_{0}^{2}+2\right) / 3\right]^{4}$.

All the nonlinear absorption coefficients of TPEtAu are listed in TABLE I with an estimated error of $\pm 5 \%$.

TABLE I: NONLINEAR ABSORPTION COEFFICIENTS OF TPEtAu

The results exhibit that TPEtAu possesses a large third-order NLO properties, which can be understood from its structure. The extended electronically delocalized core comprising the central $\mathrm{Au}^{3+}$ ion, four $\mathrm{S}$ atoms and the adjacent $\mathrm{C}=\mathrm{C}$ units is possessed of the striking physical characteristics of TPEtAu. $\mathrm{Au}^{3+}$ takes the place of group 12 metal ions $\left(\mathrm{Zn}^{2+}, \mathrm{Cd}^{2+}\right.$ and $\left.\mathrm{Hg}^{2+}\right)$, the electron delocalizations are enhanced due to the unfilled d electron shells of $\mathrm{Au}^{3+}\left(5 \mathrm{~d}^{8}\right.$ electronic configuration) that allow the possibility of low-energy charge-transfer transitions. In addition, the $3 \mathrm{p}$ orbitals of $\mathrm{S}$ and $5 \mathrm{~d}$ orbitals of $\mathrm{Au}^{3+}$ can overlap to form a highly delocalized system. The delocalization will strongly enhance the hyperpolarizability and the nonlinear susceptibility, and lead to large third-order NLO properties.

To evaluate the suitability of a material for all-optical integrated devices, we often use two figures of merit: $W=n_{2} I / \alpha_{0} \lambda$ and $T=\beta \lambda / n_{2}$. Since this sample solution exhibits very small linear absorption $\alpha_{0}$ throughout the near infrared region, the $\mathrm{W}$ values are ideal, i.e., $\mathrm{W}>>1$. Due to the slight nonlinear absorption at 1064 $\mathrm{nm}$, the value of $\mathrm{T}$ is very small approximately as 0 . Both the $\mathrm{W}$ and $\mathrm{T}$ values satisfy the requirements for the application of all-optical switching.

\section{CONCLUSIONS}

An organo-metallic material, TPEtAu is prepared and the NLO properties of its acetonitrile solution with a concentration of $1 \times 10^{-3} \mathrm{~mol} / \mathrm{L}$ are investigated by the $\mathrm{Z}$ scan technique at 1064 and $532 \mathrm{~nm}$ with $20 \mathrm{ps}$ laser duration. The third-order nonlinear refraction coefficient $n_{2}$, RSA coefficient $\beta$ and molecular second hyperpolarizability $\gamma$ are obtained, respectively. Two figures of merit, $\mathrm{W}$ and $\mathrm{T}$ values well satisfy the requirements for the application of all-optical switching at $1064 \mathrm{~nm}$. The large nonlinear refractive index; small linear and NLO absorption at $1064 \mathrm{~nm}$, make TPEtAu a promising candidate for the applications in all-optical switching at near infrared region.

\section{ACKNOWLEDGMENT}

The authors thanks the financial support of the Natural Science Foundation of Education Department of Hunan Province (Nos. 12C0311), the Hunan Provincial Natural Science Foundation of China (No. 13JJB010 and 13JJB015), and the National Natural Science Foundation(Grant Nos. 11264013). 


\section{REFERENCES}

[1] S. Salmani, E. Safari, M.H. Majles Ara, M.S. Zakerhamidi, "Investigation of the optical bistability in the PMMA polymer doped with MNA," Journal of Molecular Liquids, vol. 199, Nov. 2014, pp. 79-82, doi: 10.1016/j.molliq.2014.07.041.

[2] Hussain Ali Badran, "Thermal lens and all optical switching of new organometallic compound doped polyacrylamide gel," Results in Physics, vol. 4, 2014, pp. 69-72, doi: 10.1016/j.rinp.2014.05.004.

[3] W. Blau, H. Byrne, W. M. Dennis, and J. M. Kelly, "Reverse saturable absorption in tetraphenylporphyrins," Optics Communications, vol. 56, Nov. 1985, pp. 25-29, doi: 10.1016/0030-4018(85)90059-8.

[4] Yun-Dong Zhang, Zhen-Yu Zhao, Cheng-Bao Yao, Lan Yang, Jin Li, Ping Yuan, "The nonlinear absorption and optical limiting in phenoxy-phthalocyanines liquid in nano- and femto-second regime: Experimental studies," Optics \& Laser Technology, vol. 58, Jun. 2014, pp. 207-214, doi: 10.1016/j.optlastec.2013.11.022.

[5] T. Fathollahi Khalkhali, B. Rezaei, A. Soltani Vala, M. Kalafi, "Design of high-Q polystyrene nonlinear cavity for ultrafast alloptical switching in mid-infrared photonic crystal slabs with cavity-waveguide structure," Optics Communications, vol. 326 , Sep. 2014, pp. 43-47, doi: 10.1016/j.optcom.2014.04.020.

[6] K.B. Manjunatha, R. Dileep, G. Umesh, B. Ramachandra Bhat, "Study of third-order nonlinear optical and all-optical switching properties of palladium metal-organic complex," Optical Materials, vol. 35, May 2013, pp. 1366-1372, doi: 10.1016/j.optmat.2013.02.002.

[7] K.B. Manjunatha, R. Dileep, G. Umesh, M.N. Satyanarayan, B. Ramachandra Bhat, "All optical nonlinear and switching characteristics of a novel ruthenium complex," Optical Materials, vol. 36, Apr. 2014, pp. 1054-1059, doi: 10.1016/j.optmat.2014.01.029.

[8] M. Falconieri, R.D. Amato, A. Furlani, M.V. Russo, "Z-scan measurements of third-order optical non-linearities in poly(phenylacetylenes)," Synthetic Metals, vol. 124, Oct. 2001, pp. 217-219, doi: 10.1016/S0379-6779(01)00455-6.

[9] Qichun Zhang, Peiji Wu, Shuqing Sun, Daoben Zhu, Ming Xong, Zhesheng Ma, Nicheng Shi, "New bisdithiolene metal complex of the 2-thioxo-1,3-dithiole-4,5-dithiolato(dmit) ligand. Preparation, structure and physical properties," Synthetic Metals, vol. 98, Dec. 1998, pp. 103-106, doi: 10.1016/S0379-6779(98)00152-0.
[10] Qi Fang, Hong Lei, Chun-Li Guo, Wen-Tao Yu, Wei Xu, Dao-Ben Zhu, "Synthesis, structure and charge state of the 1:4 molecular conductor $\left(\mathrm{n}-\mathrm{Bu}_{4} \mathrm{~N}\right)\left[\mathrm{Ni}(\mathrm{dmit})_{2}\right]_{4} \cdot \mathrm{MeCN}, "$ Inorganic Chemistry Communications, vol. 13, Apr. 2010, pp. 518-521, doi: $10.1016 /$ j.inoche. 2010.01 .026 .

[11] K.B. Manjunatha, R. Dileep, G. Umesh, B.Ramachandra Bhat "Nonlinear optical and all-optical switching studies of novel ruthenium complex," Optics \& Laser Technology, vol. 52, Nov. 2013, pp. 103-108, doi: 10.1016/j.optlastec.2013.04.019.

[12] Sun Jing, Zhao Yikun, Wang Xinqiang, Ren Quan, Chen Jingwei, Zhang Guanghui, Xu Dong, and Wang Hezhou, "Nonlinear Optical Studies of $\left[\left(\mathrm{C}_{4} \mathrm{H}_{9}\right)_{4} \mathrm{~N}\right]\left[\mathrm{Ni}(\mathrm{dmit})_{2}\right]$ by Z-scan Technique," Chinese Physics Letters, vol. 28, Oct. 2011, pp. 107803, doi: 10.1088/0256307X/28/10/107803.

[13] J. Sun, W.F. Guo, X.Q. Wang, G.H. Zhang, X.B. Sun, L.Y. Zhu, Q. Ren, D. Xu, "Nonlinear optical absorption studies of an organometallic complex by Z-scan technique," Optics Communications, vol. 280, Dec. 2007, pp. 183-187, doi: 10.1016/j.optcom.2007.07.059.

[14] W.F. Guo, X.B. Sun, J. Sun, X.Q. Wang, G.H. Zhang, Q. Ren, D $\mathrm{Xu}$, "Nonlinear optical absorption of a metal dithiolene complex irradiated by different laser pulses at near-infrared wavelengths,' Chemical Physics Letters, vol. 435, Feb. 2007, pp. 65-68, doi: 10.1016/j.cplett.2006.12.057.

[15] Mansoor Sheik-Bahae, Ali A. Said, Tai-hui Wei, David J. Hagan, and E. W. Van Stryland, "Sensitive Measurement of Optical Nonlinearities Using a Single Beam," IEEE Journal of Quantum Electronics, vol. 26, Apr. 1990, pp. 760-769.

[16] G. Steimecke, H.J. Sieler, R. Kirmse, E. Hoyer, "1,3-dithiol-2 thion-4,5-dithiolat aus schwefelkohlenstoff und alkalimetall," Phosphorus Sulfur, vol. 7, 1979, pp. 49-55, doi 10.1080/03086647808069922.

[17] P.B. Chapple, J. Staromlynska, J. A. Hermann, T.J. Mckay, RG Mcduff, "Single-beam Z-scan:measurement techniques and analysis," J. Nonlinear Opt. Phys. Mater., vol.6, Sep. 1997, pp. 251-293, doi: 10.1142/S0218863597000204

[18] Q.H. Gong, Y.X. Sun, Z.J. Xia, Y.H. Zou, J. Z.N. Gu, X.H. Zhou, D. Qiang, "Nonresonant third- order optical nonlinearity of allcarbon molecules $\mathrm{C}_{60}$," Journal of Applied Physics, vol. 71, 1992 pp. 3025-3026, doi: 10.1063/1.351391 